\title{
Trabalhonecessário
}

Issn: 1808 - 799X

ano 10, no 14 - 2012

\section{ESCUELA Y TRABAJO, ¿CONSTRUCCIÓN COMUNITARIA?}

\author{
Dra. Claudia Madrid Serrano ${ }^{1}$
}

\section{Introducción}

Sea que se sitúen conceptualmente en su ámbito, sea que se pongan fuera de ella o sea que construyan conceptos paralelos, la mayoría de los discursos teóricos e ideológicos producidos en las Ciencias Sociales, a finales del siglo XX y en lo que va del XXI, giran en torno a la globalización; fenómenos como la transnacionalización financiera, la expansión de los mercados, la migración de la mano de obra de zonas rurales a urbanas, la degradación ambiental entre otros, son explicados desde el fenómeno de la globalización. Específicamente, las interpretaciones sobre este fenómeno, pensadas desde el contexto latinoamericano y desde una visión objetiva y por ello, crítica de los resultados negativos que la globalización ha tenido en las condiciones de vida de la población latinoamericana, aún se vienen construyendo. Destaco la perspectiva de Marini (1996) quien afirma que el proceso mundial al que ingresamos desde la década de los ochenta, llamado globalización, está caracterizado por una progresiva superación de las fronteras nacionales dentro del marco del mercado mundial, la alteración de la geografía política, las relaciones internacionales, la organización social, los valores y las configuraciones ideológicas particulares de los países; reconoce como relevante en este proceso la magnitud de

\footnotetext{
${ }^{1}$ Dra. en Ciencias Antropológicas, Universidad Autónoma Metropolitana; profesora-investigadora en Universidad de La Ciénega del Estado de Michoacán de Ocampo. Verdes
} 
la población involucrada en su desarrollo; La aceleración del tiempo histórico; la enorme capacidad de producción que está en juego y la profundidad y rapidez que comienzan a presentar las transformaciones que viene suscitando. Concluye que la globalización:

"corresponde a una nueva fase del capitalismo, en la cual, por el desarrollo redoblado de las fuerzas productivas y su difusión gradual en escala planetaria, el mercado mundial llega a su madurez, expresada en la vigencia cada vez más acentuada de la ley del valor. En este contexto el ascenso del neoliberalismo no es un accidente, sino la palanca por excelencia de que se valen los grandes centros capitalistas para socavar a las fronteras nacionales a fin de despejar el camino para la circulación de sus mercancías y capitales."

Circunstancia que pone en una situación de extremada precariedad a la población trabajadora de la región por cuanto la sobreexplotación y la dependencia tecnológica de nuestros países hacia los desarrollados, se ve profundizada sin que los Estados tengan la capacidad para detener dicho proceso; por el contrario la implementación de los llamados Planes de ajuste estructural, aplicados por diferentes gobiernos en los países latinoamericanos a partir de la década de los ochenta va dejando en un mayor grado de vulnerabilidad a la población, especialmente la trabajadora que ve reducidas sus posibilidades de mejoría y en algunos casos de sobrevivencia misma. La realidad de las privatizaciones, la flexibilidad laboral, la desregulación financiera y el progresivo aumento de la centralidad de la empresa en las funciones del estado, van generando la erosión de las leyes laborales, la expropiación de los recursos y del patrimonio común

Que ha generado una enorme masa de despedidos, desposeídos y desplazados hombres y mujeres, en sectores urbanos y rurales; niños fuera del espacio educativo y lúdico y lanzados al trabajo, la calle, prostitución, mendicidad, lo que es en palabras del Gilly (2004) un proceso de mezcla y fermentación permanente y brutal de la fuerza de trabajo y de las clases subalternas, que tiene lugar en los territorios y espacios de vivienda nuevos situados en los márgenes de los procesos productivos y de los centros urbanos. Es en suma la fragmentación de la vida y del imaginario de nación y futuro que la población había construido en

\footnotetext{
${ }^{2}$ íbid, p. 66
} 
décadas pasadas, y que ha sido un proceso altamente costoso para los latinoamericanos.

Es en este contexto que el presente trabajo busca mostrar la forma en que la relación educación-trabajo, relación central en la construcción de las sociedades modernas, está en transformación y que es necesario reelaborar desde un lugar crítico, la manera en que dicha relación tomó cuerpo en sociedades como las nuestras pues si bien, contribuyó en gran medida a la conformación del estado nacional, significó una ruptura profunda de los referentes culturales en las sociedades indígenas; fundamento esta afirmación desde el análisis concreto de la presencia de la escuela en una comunidad tepehua -Huehuetla, Hidalgo- mostrando como la relación educación-trabajo no tiene sustento en ésta y más bien, resultan contradictorias en el contexto de esta comunidad. Comienzo por ello con una exposición de los cuestionamientos que esta relación está teniendo en el contexto de la globalización neoliberal; para posteriormente elaborar una breve reconstrucción de la forma en que se configura el trabajo en las sociedades modernas y a su vez, de la introducción del sistema escolar en esta misma, indicando como ésta última consolida el horizonte productivo, político y cultural que subyace en el tipo de trabajo privilegiado en las sociedades industriales, para finalmente, mostrar la experiencia de esta relación entre los tepehuas.

\section{Trabajo y educación en el contexto de la globalización}

Durante la década de los noventa en América Latina, asistimos en el ámbito de las Ciencias Sociales, a la discusión de la emergencia de "nuevos sujetos sociales" que lleva a todo un replanteamiento de qué, quienes y dónde están los protagonistas del cambio social, toda vez que las condiciones de estancamiento de las economías va generando una gran masa de trabajadores despedidos, con lo que el trabajo primero y el trabajador después van apareciendo desdibujados: la actividad como boleto de entrada al progreso en todos los niveles: económico, educativo, social, cultural; el sujeto como clase, pero fundamentalmente como agente de cambio. Parte de esta pérdida para el sujeto, opera también en la lógica del sentido común como una pérdida de prestigio político y social. Así, sentido común y teoría explicativa, ajustan 
su mirada más que al concepto de "clase" al de "sectores", grupos definidos, a decir de Kuper (2000). Discusión que sigue presente toda vez que la condición de precariedad social resultado de la aplicación de las políticas neoliberales, se profundiza en los primeros años de este siglo. $Y$ se muestra con crudeza en la fragmentación de la vida y del imaginario de nación y futuro que la población había construido en décadas pasadas.

En el destierro en la vida cotidiana y concreta de la población, de la posibilidad del desarrollo y de mejores futuros como sociedad y que se refleja en la manera como aparecen representados nociones centrales de esa posibilidad. A saber:

Bajo una mirada progresiva, la educación era equivalente a trabajo; trabajo equivalente a ingreso; ingreso a bienestar familiar y el bienestar familiar, equivalente a desarrollo social.

Ahora, la educación no es equivalente al trabajo; el trabajo no es equivalente al ingreso; el ingreso al bienestar familiar y el bienestar familiar (sobre todo si al hablar de bienestar familiar, nos referimos a una parte mayoritaria de la población) no equivale a desarrollo social.

De tal modo que podemos reducir nuestra inequivalencias a que el trabajo no es igual al desarrollo social. Y en el terreno político estas desigualdades se traducen en las siguientes:

Antes: el trabajo era equivalente a obrero; obrero a conciencia de clase, y de ahí a que éste se erigía como agente de cambio. El desprestigio político que ha venido junto al despido masivo o incluso a trabajadores no despedidos, simplemente porque no fueron incorporados al mercado laboral, ha trastocado por completo al obrero como clase política y por ahí, como protagonista revolucionario. 


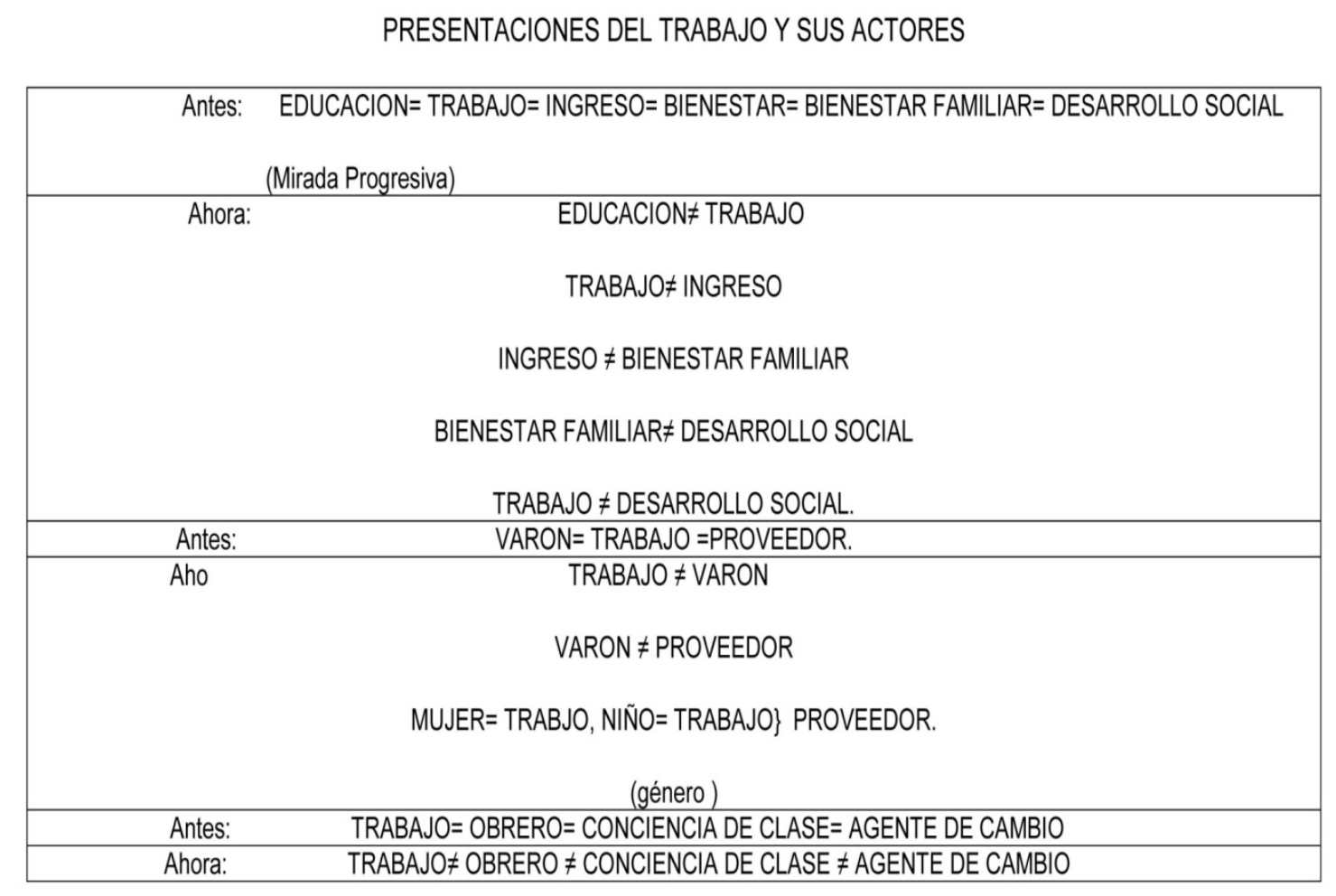

En este mismo escenario encontramos que si bien antes el varón era sujeto de trabajo y por tanto, proveedor a la familia, hoy es la mujer ${ }^{3}$ y en cada vez mayor número, los niños.

Así que lo que tenemos como sociedad bajo el neoliberalismo, además de unos sujetos atomizados, es la pérdida de referentes que den sentido a la necesaria cohesión social y por tanto, la persistencia de la comunidad, toda vez que lo único

\footnotetext{
3 "Durante las décadas de 1980 y 1990 la participación de las mujeres en los mercados de trabajo del mundo aumentó considerablemente. (...) En números absolutos, más mujeres que nunca antes participan en los mercados de trabajo del mundo. (...) ellas están empleadas o buscan activamente un empleo. (...) la participación femenina en el empleo total se ha mantenido casi sin alteraciones en 40 por ciento en 2006 frente a 39.7 por ciento diez años atrás", no obstante indica que si bien había una expectativa de que el ingreso al trabajo mejoraría la condición material de las mujeres, las inequidades que se registran en el ámbito laboral en cuanto a los sectores, condiciones laborales y salariales en que se desempeñan no cumplieron estas expectativas, "Las mujeres tienen más probabilidades de ocupar puestos de trabajo de baja productividad en la agricultura y los servicios. Hay evidencias sobre la persistencia de una diferencia salarial. (...) En la mayoría de las regiones y en muchos tipos de ocupación, las mujeres reciben menos dinero por el mismo empleo." UNICEF (2007).
} 
que se toma como cierto es la incertidumbre, con sus cargas de temor e inmovilidad que eso genera, especialmente en la población juvenil. ${ }^{4}$

Un futuro compartido: estaba el qué, el cómo, los porqués. No es que afirme que la sociedad marchaba, sin contradicciones violentas y como una masa compacta, pero en cierto modo, los lugares de llegada se mostraban más claros. La figura misma del Estado se nos ofrecía como la institución -nunca sin violenciagarante de la protección jurídica y social, en la relación trabajo-capital, al mismo tiempo, como interlocutor específico en las negociaciones por mejorar las condiciones de vida sociales. De este modo, un encuentro en "nuestra nación" ofrecía ciertas miradas comunes sobre la manera en que la vida debía discurrir, y en las cuales la conexión educación-trabajo juegan el fundamental papel de otorgar certezas tanto a la condición profesional como de vida, hoy en día como indiqué antes, cuestionada. En los siguientes apartados me ocupo de elaborar una breve reconstrucción del trabajo en la modernidad y de la aparición de la escuela, desde una perspectiva marxista y retomando ideas principales expresadas por Julia Varela para hablar de la escuela. La intención de esta reconstrucción es mostrar cómo el tipo de trabajo privilegiado en la modernidad industrial, como la concepción sobre la que se sustenta la creación de la escuela, son en muchos sentidos, contrarios a la construcción de un proyecto social y comunitario, recuperador de maneras de socialización, aprendizaje y formación, independientes del control político del estadonación

\footnotetext{
${ }^{4}$ Según datos de la Primera Encuesta Nacional Exclusión, Intolerancia y Violencia en Escuelas Públicas de Educación Media Superior, realizada por la Instituto Nacional de Salud Pública (2007) a estudiantes de educación media de subsistemas federales, estatales y autónomos, de entre 15 y 19 años, el 79.6\% de estudiantes mujeres se sintió triste; $45.2 \%$ creyó que su vida había sido un fracaso; $60 \%$ se sintió sola; mientras que entre estudiantes hombres, los porcentajes fueron de $61.6 \%$, 35.7\% y $44.7 \%$, respectivamente. Así mismo, 46.4\% de estudiantes mujeres han vivido situaciones que les hacen desear dejar de existir; $42.6 \%$ han tenido una sensación de que no vale la pena vivir y $30.5 \%$ han pensado que vale más morir que vivir; en el caso de estudiantes hombres los porcentajes son de $28.9 \%, 28.7 \%$ y $19 \%$ respectivamente. $Y$ en ambos sexos, el $84.9 \%$ se ponen nerviosos con muchas cosas; $62.9 \%$ se asusta con facilidad y el $58.5 \%$ tienen dificultades para hacer amigos. Considero que estos datos son reveladores de la manera en que las dificultades económicas y la fragmentación social ha impactado negativamente en los jóvenes.
} 


\section{El trabajo en la modernidad. Su dimensión económica, política y cultural}

El trabajo como categoría de análisis es una de las piedras angulares del discurso económico, sea éste elaborado bajo la tradición de la economía clásica o neoclásica. En la teoría marxista el trabajo constituye la parte fundamental de su obra, pues en éste se sustenta la teoría del valor, que representa a su vez el nódulo de la crítica que elabora a la Economía Clásica y su punto fundamental de distanciamiento que es también el sustento teórico de su discurso político.

La diversidad conceptual con la que Marx [1867(2001)] se refiere al trabajo y su análisis en torno al valor y a la especificidad del capital como un modo de producción fundado en la explotación del trabajo ajeno son las razones por las cuales elaboro ahora una exposición que pretende ser breve pero precisa en torno a ello ${ }^{5}$.

Su análisis comienza con la mercancía, toda vez que "La riqueza de las sociedades en las que domina el modo de producción capitalista se presenta como un "enorme cúmulo de mercancías", y la mercancía individual como la forma elemental de esa riqueza."

Indicando ya que la mercancía es un objeto que posee valor de uso, en tanto es útil para la satisfacción de una necesidad humana específica; y valor de cambio que se presenta como relación cuantitativa-, es decir una proporción en que se intercambian valores de uso de una clase por otros de otra clase. Pero que poseen algo en común: ser productos del trabajo humano, “...si ponemos a un lado el valor de uso del cuerpo de las mercancías, únicamente les restaría una propiedad: la de ser productos del trabajo" (p. 46) y haciendo abstracción de las cualidades diferenciadas de estos valores de uso, tanto como de los diversos trabajos del que son producto éstos se reducen a ser trabajo humano indiferenciado, esto es a lo que llama Marx trabajo abstractamente humano.

\footnotetext{
${ }^{5}$ Bajo esta consideración es que retomo las distintas conceptualizaciones que Marx ofrece en torno al trabajo, no sólo por la riqueza conceptual que ello implica, sino porque son conceptos cuya explicación da cuenta de procesos sociales e históricos bajo los cuales tanto éste (el trabajo) y el contexto en donde se desarrolla, fueron transformándose.
} 
Lo que se hace evidente es que más allá de sus cualidades singulares, estos distintos valores de uso tienen en común la misma objetividad: que en ellos se empleo fuerza de trabajo humano, por lo que en cuanto cristalizaciones de esa sustancia social común a ellas, son valores. (p. 47).

Así estos valores de uso, sólo tienen valor porque en ellos está objetivado o materializado trabajo abstractamente humano. $Y$ cuya medida es resultado del gasto de trabajo medio social usado en la producción de dicho valor de uso o dicho de esta manera como el tiempo de trabajo socialmente necesario, que es definido como el requerido para producir un valor de uso cualquiera, en las condiciones normales de producción vigentes en una sociedad y con el grado social medio de destreza e intensidad de trabajo. (p. 48)

Este concepto también nos sirve para precisar lo que Marx llama la cualidad bifacética de la mercancía ${ }^{6}$, a partir de considerar que la mercancía es tanto valor de uso y por ello, producto de trabajo concreto; mientras que al ser útil para el cambio, se difuminan sus cualidades específicas y singulares, lo mismo que del trabajo que le dio origen, por lo que es también producto de un trabajo abstracto.

Para producir a la mercancía como un valor de uso que satisface una necesidad específica se requiere una determinada actividad productiva útil, llama así trabajo útil al trabajo cuya utilidad se representa en el valor de uso de su producto. Por otro lado, los trabajos por los cuales existen, son cualitativamente distintos lo que hace posible que se contrapongan como mercancías; esto es que sólo los productos de trabajos privados autónomos, recíprocamente independientes pueden enfrentarse como mercancías. Este doble carácter de la mercancía refiere por tanto, a la dualidad en el trabajo contenida en ella.

Esta dualidad con la que se presentan las mercancías en el capitalismo, se les presenta a los sujetos bajo un carácter enigmático en la medida en que ésta misteriosa forma refleja ante los hombres el carácter social de su propio trabajo como caracteres objetivos inherentes a los productos del trabajo, como propiedades

\footnotetext{
6 "He sido el primero en exponer críticamente en exponer esa naturaleza bifacética del trabajo contenido en la mercancía. Como este punto es el eje en torno al cual gira la comprensión de la economía política, hemos de dilucidarlo aquí con más detenimiento" Marx, p. 51.
} 
sociales naturales de dichas cosas, y por ende, en que también refleja ante la relación social que media entre los productores y el trabajo global, como una relación social entre los objetos al margen de los productores. (p.88)

Al mismo tiempo que establece que si los valores de uso se convierten en mercancías es porque son a su vez, productos de trabajos privados, ejercidos independientemente los unos de los otros, siendo el complejo de ellos lo que constituye el trabajo social global.

Estas características de las mercancías es lo que Marx llama "fetichismo7 de la mercancía" que alude a la forma en que las mercancías -en tanto resultado del trabajo- se presentan ante el productor como un ente ajeno a éste. Argumenta que esto es así porque los productores no entran en contacto directo a través de su trabajo individual, sino a partir del intercambio del producto de su trabajo convertido en mercancías. ${ }^{8}$ Este concepto implica dar cuenta al mismo tiempo de la perspectiva histórica en que se centra su análisis del capitalismo como modo de producción transitorio en el desarrollo social, en la medida en que explica relaciones sociales y productivas diferenciadas: entre el sujeto y el producto de su trabajo; y entre los sujetos. Diferenciando trabajos privados de trabajos colectivos, y las relaciones que ellos generan; categorías que se presentan de formas diferenciadas en la sociedad y que definen el tipo de organización socioeconómica existente. Muestra ejemplos de cómo en la historia esta relación y trasposición entre trabajos privados y colectivos no ha sido la regla, más aún de cómo en sociedades donde el trabajo es directamente colectivo -esto es que no sea necesaria la mediación del mercado, para que se efectivice entre los productores como tal- los trabajos y productos no

\footnotetext{
${ }^{7}$ Es pertinente la aclaración del uso que hace del concepto de "fetiche" como un objeto material al que se le confieren cualidades subjetivas; y en tanto es un producto del trabajo, cuando se le adjudican propiedades mágico religiosas, aparece ajeno al mundo material de los hombres y producto del mundo sobrenatural.

${ }^{8}$ por lo que los trabajos privados no alcanzan realidad como partes del trabajo social en su conjunto, sino por medio de las relaciones que el intercambio establece entre los productos del trabajo y, a través de los mismos, entre los productores. Á estos por ende las relaciones sociales entre sus trabajos privados se les ponen de manifiesto como lo que son, vale decir, no como relaciones directamente sociales trabadas entre las personas mismas, en sus trabajos, sino por el contrario como relaciones propias de cosas entre las personas y relaciones sociales entre las cosas.(p. 89)
} 
asumen una forma fantástica diferente de su realidad, por lo que la forma natural del trabajo, su particularidad, y no, como sobre la base de la producción de mercancías, su generalidad, es lo que aquí constituye la forma directamente social de aquél.

Siguiendo con esta línea argumental, después de presentar a la dualidad del trabajo como el elemento central en la producción de mercancías, explica cómo ocurre el proceso de trabajo en su forma histórica general como productor de valores de uso, y bajo su forma histórica particular, como productor de plusvalor, a decir de él, como proceso de valorización ${ }^{9}$. Nos ofrece aquí una definición de trabajo: El trabajo es, en primer lugar, un proceso entre el hombre y la naturaleza, un proceso en que el hombre media, regula y controla su metabolismo con la naturaleza.

Al cual además, presenta como una actividad que humaniza al hombre y que lo separa del mundo animal y que constituye también la tesis central del texto "El papel del trabajo en la transformación del mono en hombre" de F. Engels: El trabajo es la fuente de toda riqueza, afirman los especialistas en Economía política. Lo es, en efecto, a la par que la naturaleza, proveedora de los materiales que él convierte en riqueza. Pero el trabajo es muchísimo más que eso. Es la condición básica y fundamental de toda la vida humana. Y lo es en tal grado que, hasta cierto punto, debemos decir que el trabajo ha creado al propio hombre. (...)Primero el trabajo, luego y con él la palabra articulada, fueron los dos estímulos principales bajo cuya influencia el cerebro del mono se fue transformando gradualmente en cerebro humano. (2000)

Pero ¿cuál es la singularidad del trabajo del hombre sobre otro tipo de actividad que desarrollan, por ejemplo las abejas?, proviene, sostiene el autor de que a diferencia de éste último, el del hombre ocurre bajo una finalidad, que él prefigura intelectualmente: concebimos al trabajo bajo una forma en la cual pertenece exclusivamente al hombre, en la medida en que éste tiene una intencionalidad: 10 que distingue ventajosamente al peor maestro albañil de la mejor abeja es que el primero ha modelado la celdilla en su cabeza antes de construirla en la cera, de modo que al mismo tiempo que transforma la naturaleza, se objetiviza: el obrero no sólo efectúa un cambio de forma de lo natural; en lo natural, al mismo tiempo,

\footnotetext{
${ }^{9}$ Planteamiento que desarrolla en el capítulo 5, bajo el título de "Proceso de trabajo y Proceso de valorización".
} 
efectiviza su propio objetivo, objetivo que él sabe que determina, como una ley, el modo y manera de su accionar y al que tiene que subordinar su voluntad.

Estableciendo esta condición del trabajo, pasa a explicar en qué consiste el proceso de trabajo y la manera en que se interrelacionan sus elementos: los elementos simples del proceso laboral son la actividad orientada a un fin -o sea el trabajo mismo-, su objeto y sus medios.

De la finalidad a que éste se conduzca y de la forma en que el objeto de trabajo se opere -es decir del medio de trabajo empleado- depende el tipo de organización productiva que define a su vez de qué tipo de sociedad se trate (desde el punto de vista económico): lo que diferencia unas épocas de otras no es lo que se hace, sino cómo, con qué medios, de trabajo se hace.

Observo también aquí esta perspectiva histórica que ya ha señalado el autor en el análisis del objeto mercantil que antes he presentado.

Su exposición puntual de la forma en que se desarrolla el proceso de trabajo, deriva en señalar que el trabajo en tanto productor de valores de uso, es trabajo productivo, haciendo referencia con esto al proceso de trabajo en su forma histórica general; y en seguida mostrará la forma en que este proceso se transforma en proceso de valorización, -proceso de trabajo en su forma histórica particularidentificando a la fuerza de trabajo - uno de los elementos del proceso de trabajocomo la creadora de valor, de trabajo vivo y situando al medio de trabajo, como el elemento que transfiere valor, de ahí que lo denomine portador de trabajo muerto.

En adelante su análisis si bien mantendrá como referencia estas dos realidades históricas, estará centrado en mostrar cómo es que bajo la modalidad del proceso de trabajo como proceso de valorización, ocurre la explotación de la fuerza de trabajo, indicada ya en términos de la jornada laboral capitalista, bajo la categoría de trabajo excedente denominado también plustrabajo toda vez que es éste el que produce el plusproducto o plusvalor ${ }^{10}$ y que es además uno de sus componentes, siendo el otro el trabajo necesario, definido como la parte de la jornada en que el

\footnotetext{
${ }^{10}$ Denominamos plusproducto (...) la parte del producto (...) que representa el plusvalor (...) Y del mismo modo que la producción de plusvalor es el objetivo fundamental de la producción capitalista, no es la magnitud absoluta del producto, sino la magnitud relativa del plusproducto lo que mide el grado alcanzado por la riqueza p. 276.
} 
obrero produce lo necesario para producir diariamente su fuerza de trabajo. Ambos trabajos por tanto son lo que constituye la jornada de trabajo: la suma del trabajo necesario y del plustrabajo, de los lapsos en que el obrero produce valor sustitutivo de su fuerza de trabajo y el plusvalor, respectivamente, constituye la magnitud absoluta de su tiempo de trabajo: la jornada laboral (working day)(p.276).

Finalmente lo que se analiza es el trabajo como creador de valor en la sociedad capitalista.

Desde una dimensión política el trabajo confiere al trabajador la categoría de sujeto político, presente ya en el movimiento cartista del siglo XIX, que dará origen a la conformación de sindicatos, figura de interlocución para el estado en el marco de la relaciones obrero-patronales, al mismo tiempo que espacio de gestión y actividad política para una gran cantidad de individuos en su calidad de obreros.

Habrá que agregar además la reestructuración que la cotidianidad sufre a partir de la introducción del trabajo como actividad fundamental económica y de carácter masivo, que poco a poco lleva a una disminución importante del tiempo dedicado al ocio y a actividades lúdicas. ${ }^{11}$ Más aún habrá que agregar que el trabajo y el espacio donde se desarrolla, es ahora el primero, uno de los principales medios para estrechar los vínculos sociales; el espacio laboral, un lugar de reunión. Es en éste en donde se estructura una gran parte del proyecto personal y familiar y sobre el que descansan las expectativas de formación de los sujetos, las cuales están en correspondencia con aquello que un grupo humano valora como lo socialmente legítimo. Una de las dimensiones que se encuentran también en el trabajo es la cultural, sumamente importante por cuanto que el trabajo, no puede ser visto únicamente como productor de riqueza, sino también de sentidos. En su análisis en la tradición antropológica mexicana, fue visto como un elemento más de la llamada

\footnotetext{
${ }^{11}$ Hecho que enfatiza Aríes (2001) al describir como se sustituye el juego por el trabajo y cómo es que éste adquiere un sentido distinto para nuestra existencia, en la antigua sociedad, el trabajo no ocupaba tantas horas al día, ni tenía tanta importancia para la opinión pública: no tenía el valor existencial que nosotros le damos desde hace más de un siglo. Casi se puede decir que no tenía el mismo sentido. Por el contrario, los juegos, las diversiones, se prolongaban mucho más de los momentos furtivos que nosotros les concedemos: formaban uno de los principales medios de que disponía la sociedad para estrechar sus vínculos colectivos, para sentirse reunidos. (p. 107).
} 
cultura material de los grupos sociales que ésta estudia. Una parte importante del trabajo etnográfico construido sobre sociedades tradicionales y diversas monografías, han permitido tener acceso al conocimiento de distintas técnicas y procesos productivos a su interior; sin embargo se registra un vacío importante en cuanto a considerar el trabajo como una dimensión de análisis específica (Raúl Nieto, 1997), no obstante su centralidad para entender además del proceso productivo, elementos de su cosmovisión. Mientras tanto en el caso, de las sociedades occidentales, el análisis de la categoría del trabajo, que sobra decir, se consideraba sólo como trabajo industrial, no fue objeto de estudio para la antropología; en gran medida porque ello significaba en cierto modo trastocar la tradición antropológica, que en definitiva buscaba la alteridad en las sociedades tradicionales, de modo que analizar el trabajo en los espacios industriales resultaba poco atractivo, por decirlo de alguna manera. Es en décadas recientes que fue mostrándose la necesidad de dilucidar qué procesos simbólicos se juegan en el mundo del trabajo y cómo estos operan en su realización, pero también en las otras dimensiones de la vida social. De este modo, pese a las vicisitudes que este campo de análisis ha tenido en la disciplina antropológica, es posible observar que el trabajo como actividad productiva no sólo produce bienes, sino también una serie de significados y sentidos que independientemente del marco social en donde se desarrolle, operan.

Un individuo trabaja y pone en juego una serie de valores, normas, representaciones y significados, que no se producen en esta esfera de su vida, pero que están presentes y a su vez, en su vida social, cotidiana, los significados que se pueden construir en la actividad productiva se hacen patentes en ésta. Dicho de otro modo, cuando un sujeto trabaja está presente el conjunto de su cultura.

En este recuento sobre el trabajo quiero ahora introducir una última discusión que tiene que ver con el aspecto ético y con la manera en que éste se transforma bajo las sociedades industriales. 
De acuerdo a Zygmunt Bauman (2000) ${ }^{12}$, con la introducción de la producción fabril se pone en marcha una cruzada moral, que consiste en introducir entre los trabajadores, valores en torno al trabajo fabril, que apoyen el principio de racionalidad mercantil subyacente a ésta. Si bien, el trabajo en la fábrica supuso la ruptura entre el artesano y su trabajo, se pretende revivir actitudes tradicionales, propias del periodo preindustrial, pero desprovistas de sentido, buscando con ello el compromiso pleno con el trabajo artesanal, la dedicación incondicional al mismo y el cumplimiento en el mejor nivel posible, de las tareas impuestas. Las mismas actitudes que -cuando ejercía el control sobre su propio trabajo- el artesano adoptaba espontáneamente (Bauman, 2000:19)

Reconoce el carácter contradictorio de tales intentos, pues se busca que el trabajador traslade los significados y el sentido que atribuía a su trabajo en condiciones en las que él no es sólo quien controla el proceso, sino además es dueño de su producto, a otras condiciones en las que esto ha desaparecido. La imposición de la ética del trabajo industrial implica la renuncia a la libertad (p.20)

De este modo, los intentos de incorporar a los individuos al trabajo fabril no sólo constituyeron una tarea económicamente útil, sino también moral. Lo que se introdujo con la ética del trabajo en las sociedades industriales y como parte de un pensamiento moderno, fue lograr separar lo que la gente hacía de lo que consideraba digno de ser hecho, de lo que tenía sentido hacer; separar el trabajo mismo de cualquier objetivo tangible y comprensible. (p. 21)

Así, lo que se apuntala es que la introducción del trabajo en la fábrica operó como un mecanismo económico, a la vez que como un mecanismo a partir del cual habría de buscarse transformar la representación que los sujetos hacían de su trabajo y del significado que éste confería a su vida.

\section{La escuela y la educación en la modernidad}

La escuela es la institución surgida en el marco de la conformación de los estados nacionales, cuya creación se constituyó en un instrumento privilegiado para lograr el

\footnotetext{
${ }^{12}$ Cuyo esquema explicativo recuerda muestra muchos acercamientos a las tesis propuestas por Marx (y resumidas brevemente en este trabajo) en torno a las transformaciones socioeconómicas que la introducción del trabajo bajo condiciones de explotación, trajo, sólo que Bauman pone el acento en la dimensión ética del trabajo.
} 
proyecto de la modernidad. Responde a las necesidades ideológico-políticas de construcción de ciudadanía, expresadas en el Contrato social y sustentadas en las ideas de libertad, justicia e igualdad, así como las de progreso y orden social. De acuerdo a este proyecto, la escuela cumple dos funciones: la de lograr la emancipación humana a partir de proveer de conocimiento a todos y por ello, promover el orden, la libertad y el progreso; la adjudicación de una sociedad civilizada pasa por la escuela; y la de lograr la democratización social, así la escuela operaría bajo dos sentidos (Díaz Barriga, 1998): buscando el acceso a la educación para todos y privilegiando el uso de la razón para lograr el conocimiento. Como espacio de aprendizaje se trasladan a ésta muchas de las funciones que se operaban en el seno de la familia o de la comunidad, de acuerdo con Ariés (2001) A fines del siglo XVII se gesta una transformación: la escuela sustituye al aprendizaje como medio de educación. El niño es separado de la cohabitación con el adulto y confinado al espacio de la escuela, cesando el aprendizaje por contacto directo con ellos: hace su aparición la escolarización. No obstante este espacio al que Julia Varela reconoce como espacio de cuarentena física y moral (Varela, 2004) no es en ningún sentido homogéneo; en éste se proyecta las diferenciaciones y estratificación social presentes en las sociedades burguesas señala que en virtud de la mayor o menor calidad de la naturaleza de los educandos y corrigendos, determinada por su posición en la pirámide social, diferirán las disciplinas, se flexibilizarán los espacios, se dulcificarán en fin los destinos de los usuarios. (Julia Varela, 2004:8)

Por otro lado la escuela y la educación se tornan centrales también para el aseguramiento del éxito del proyecto económico de la industrialización. La civilización medieval no tenía idea de la educación. La sociedad moderna depende del éxito de su sistema educativo. Tiene un sistema de educación, una concepción de la educación, conciencia de su importancia y unas ciencias recientes y específicas (Ariés op. Cit.) que le permiten la continuidad como proyecto.

Los grandes requerimientos de mano de obra calificada precisadas por la acelerada industrialización, son para la escuela uno de sus grandes incentivos. Es posible también observar por ello, que la escuela como institución del estado, asume una dimensión eminentemente económica, en la medida en que busca el 
aseguramiento de la fuerza de trabajo para la fábrica y por ello, es que suele verse a la educación como la necesaria "inversión en capital humano" que habrá de hacerse si se quiere lograr una nación desarrollada, tecnológicamente hablando. Esta perspectiva en la historia de la educación, ha sido recientemente explotada y en los tiempos que corren mayormente privilegiada toda vez que se asume a la educación y especialmente, a la educación de calidad, como la piedra de toque de la disminución de la pobreza, entendida no sólo como carencia material, sino también política, social e intelectual.

La dimensión política de la escuela, no está alejada de la perspectiva de la que surge y si bien pueden observarse en ella, elementos humanistas, es claro que reproduce las necesidades del estado, en cuanto que en ella habrán de formarse los futuros trabajadores cuya educación está encaminada ante todo a la elaboración de trabajos en la industria ${ }^{13}$; es posible por ello que Varela (op. Cit.) afirme como es que al interior de los sistemas educativos queda condensada las diferencias clasistas y las perspectivas bajo las cuales se educa a los pobres y a los hijos de las clases acomodadas. En su origen, indicará que no hay puntos de coincidencia entre la escuela y la educación para el príncipe y la educación y los espacios creados para formar a los niños pobres:

La recogida y educación de los niños pobres en instituciones a las que son destinados poco tiene que ver no sólo con la educación del Príncipe niño sino también con la de los colegiales que además de dedicarse al estudio de materias literarias (gramática, retórica, dialéctica) vedadas para los pobres y al de distintas lenguas entre las que predomina el latín, se entretienen con juegos y espectáculos cultos y adquieren cortesanas maneras mediante la danza, la esgrima, la equitación y otros ejercicios de marca que les proporcionarán lo que Pierre Bourdieu denomina una hexis corporal en consonancia con su categoría social. Pero no se trata únicamente de diferencias de contenidos y actividades sino que la dureza del encierro, el rigor de los castigos, el sometimiento a las órdenes, el distanciamiento de la autoridad, y la autopercepción que se les inculca son el fruto de la diferencia abismal que existe entre los

\footnotetext{
${ }^{13}$ Retomo la perspectiva de esta autora quien al hablar de lo que caracteriza la escuela, refiere a la escuela nacional, caracterizándola como el espacio de gobierno de los hijos de la clase desfavorecida.
} 
preceptores domésticos, los colegios y «las escuelas de primeras letras» destinadas a los hijos de los pobres. (Varela, op. Cit:13,14)

En estos espacios será posible la observación, aprendizaje y puesta en práctica de una serie de rudimentos para "educar" a los niños, dando origen a la teoría pedagógica; de los maestros que habrán de formarse, el estado espera que formen en los niños la imposición de una lengua, como lengua nacional y el empleo de distintas técnicas que los introduzcan a la lectura, escritura y el cálculo que los capacite para conocer y cumplir los deberes de su estatus de ciudadanía. (Varela, op cit.)

En lo tocante a la dimensión cultural de la educación, durante un largo periodo la disciplina antropológica desestimó el estudio de la escuela como formadora de cultura; no es sino hasta recién entrados los sesentas cuando ésta se ocupa de ella. Sin embargo más allá de que desde esta disciplina se analizara a la escuela como espacio reproductor de cultura, es innegable que en ella se condensan una serie de dispositivos culturales que o bien pueden fortalecer la previa o bien introducir otros referentes culturales a la población que se forma. En muchos sentidos, la escuela ha sido el vehículo conductor por excelencia de la introducción en las sociedades de la introducción de los sentimientos de patriotismo e ideología nacionalista, necesarias para consolidar el estado nación.

Un último aspecto que me interesa retomar de lo planteado por Varela es el que tiene que ver con su observación de la escuela como elemento de ruptura de prácticas de socialización establecidas al margen del poder político y que entrañan una continuidad entre aprendizaje y formación; la socialización, el aprendizaje y la formación operaban en forma colectiva al interior de los gremios, de este modo, el taller era lugar de vida, de trabajo y de instrucción, coexistiendo saberes y trabajo productivo (Varela, op, cit.) la irrupción de la escuela separa este proceso, pero también impone jerarquizaciones entre la infancia y los adultos de las clases populares, reconfigurando sus mecanismos de socialización y de acción política, toda vez que el discurso prevaleciente se orienta hacia la disciplina, hacia la introyección de que el maestro es quien tiene la autoridad y en quien habrá de recaer la gestión y 
la orientación de los saberes y quien junto con la institución escolar legitima los saberes y los conocimientos que son necesarios en la sociedad.

En este sentido, la escuela aparece como la institución necesaria para el desarrollo del capital, prolonga las rupturas que la transformación del trabajo colectivo en trabajo privado se opera en este sistema, y juntos -escuela y trabajo privado y fabril- son núcleo fundamental en la construcción de los estados burgueses.

En este punto quiero mostrar brevemente cómo ocurre este proceso al interior de una sociedad tradicional mexicana, que está en proceso de cambio, pero cuyo componente indígena aún organiza muchos de los aspectos de su socialización y de sus relaciones al interior de la comunidad y fuera de ella.

\section{Educación y trabajo entre los tepehuas}

Hoy en día es una realidad constatar que se concibe a la escuela como el vehículo formativo más importante: para el trabajo y la vida social, si bien va perdiendo cierta credibilidad que la asistencia a la misma, sirva como un mecanismo de movilidad social, especialmente porque se va operando una brecha cada vez mayor entre los niveles de bienestar socioeconómico y los niveles educativos. Martín Hopenhayn (2008) indica que los jóvenes viven una serie de disonancias, por ejemplo en cuanto a empleo se refiere, pues si bien tienen mayores niveles de escolarización, tienen cada vez menores oportunidades de empleo. De modo que aún ahora con esta pérdida de valor social, la escuela sigue jugando este papel tan importante; el trabajo que antes jugaba un papel central en la formación de los individuos, en su inserción social y en la transmisión cultural a partir de las acciones rituales va cediendo su lugar a la escuela, En ese sentido, el trabajo que entre las comunidades indígenas o fuera de ella, desarrollan los niños se ve menos con fines educativos, pues tienen claro que ésta sólo ocurre al interior de la escuela, lo cual habla no sólo del papel formador que las comunidades indígenas atribuyen a la escuela con éxito, sino también del hecho de que es muy poco probable que educar a los niños a través del trabajo en las condiciones en que se desarrolla sea la razón que está en la permisividad que tienen los padres en que sus hijos realicen diversas actividades. 
Existe una idea más arraigada ahora de que el mundo del trabajo es un mundo de dureza entre grupos indígenas, hay una reiteración permanente al hecho de que se quiere una historia diferente para los niños, en tanto no sólo se observa el elemento formador a partir de la escuela, sino también el elemento lúdico, necesario para la misma y que deriva del tiempo libre que es posible sólo en el marco de la escolarización; al mismo tiempo que se considera que una vida digna, honorable, ahora se lograría a partir de la asistencia a la escuela y no de la realización del trabajo en edades tempranas. Entre los tepehuas, ésta también es una realidad ${ }^{14}$. Los tepehuas son un grupo indígena asentado en tres estados de la República Mexicana: en los Municipios de Zontecomatlán, Ixhuatlán de Madero y Tlachichilco, del estado de Veracruz; en Mecapalapa, del estado de Puebla; y en el municipio de Huehuetla, del estado de Hidalgo. En este trabajo me refiero a ésta última comunidad en donde se asientan los tepehuas de Hidalgo. En el mapa de abajo muestro la ubicación de Huehuetla en el estado de Hidalgo, señalado como el municipio 27 y caracterizado como un municipio de extrema marginación.

\footnotetext{
${ }^{14}$ Esta parte del artículo forma parte de las conclusiones obtenidas en el trabajo de campo realizado como parte de mi tesis doctoral, en Huehuetla, cabecera municipal ubicada en la Sierra Otomí-Tepehua del estado de Hidalgo. Las personas a las que aquí hago referencia pertenecen a esta población y entre otras más, sus historias de vida formaron parta importante de la reconstrucción que elaboro sobre el ritual "curación para el trabajo".
} 


\section{Mapa 1. Ubicación Geográfica de Huehuetla.}

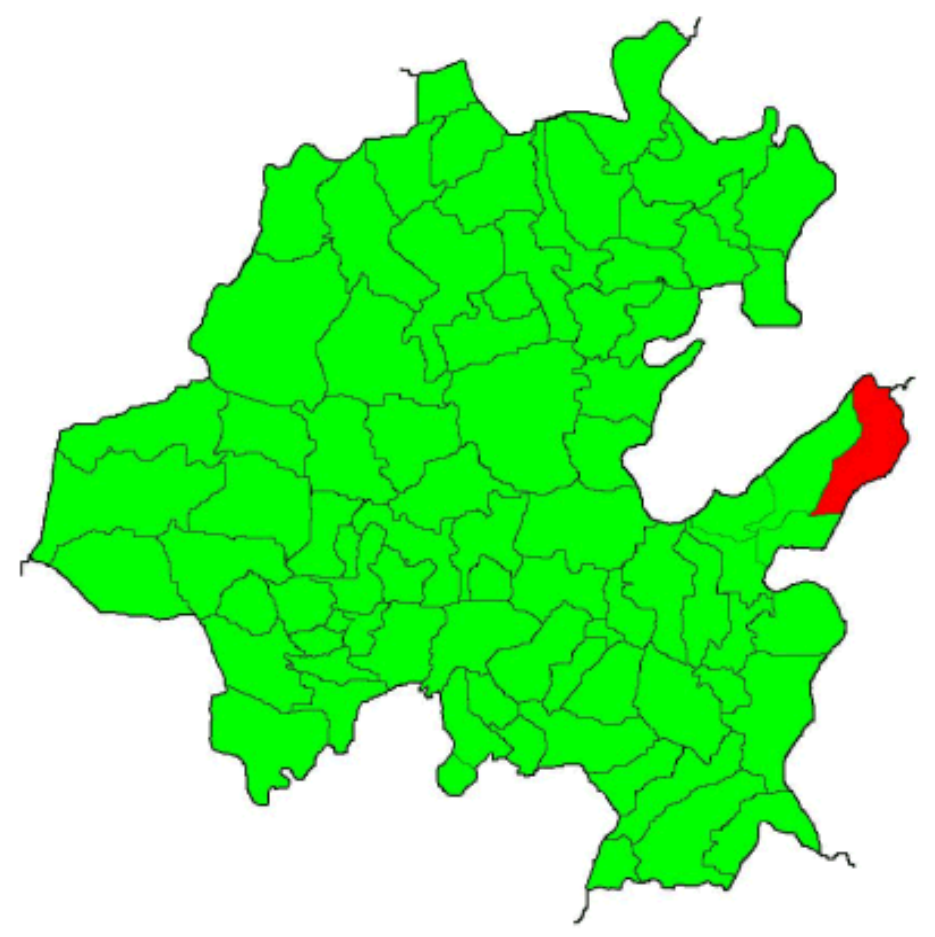

Mapa tomado de Enciclopedia de los Municipios de México, 2005

En torno a la educación se plantean una serie de problemáticas que tienen que ver con la preservación de la cultura tepehua: el primero es la enseñanza escolarizada en una lengua que no es la materna, con lo cual se opera un cambio cultural importante, y contribuye a la desvalorización social de ésta misma (lengua materna) toda vez que es la escuela quien va fortaleciendo la baja valoración social que se le ha ido asignando entre la población de la comunidad a la lengua tepehua; son comunes las referencias al uso del "idioma castilla" como el que es propio de las "gentes de razón"15, de las gentes importantes, mientras que sólo el hablar tepehua denota cierta ignorancia y pobreza; en una gran parte de la población de mayor edad de la comunidad hubo cierta coincidencia en la prohibición que se tenía en la escuela respecto de hablar en tepehua. Otro problema es el que tiene que ver con la prohibición del uso del vestido propio de los tepehuas, hecho que ya registró Williams

\footnotetext{
15 ¿Tendrá sentido esta denominación en el marco de la discusión que introduce en la teoría social Dumont (1970) al establecer esta diferencia en torno a las modernas sociedades occidentales como sociedades de razón y a las tradicionales como sociedades de creencia?.
} 
(1963), en su trabajo etnográfico sobre los tepehuas de Veracruz y que Doña Anita también refiere al señalar que cuando la retiran de la escuela, la vuelven a vestir con el liado: me mandaron a la escuela y salí como en cuarto año, pero ya no quisieron me quitaron mi blusita, me pusieron mi faldita de liado, como mi mama sabía tejer de este, pues me lo hizo y me lo cambiaron y me quedé así con mi liado ya de doce años según, mi mamá ya no quiso que fuera a la escuela(...) me quitaron mi ropa ¡cómo me gustaban mis vestidos aunque sea sencillito! Pero así nada más, nada de guarache, así pataraís.

Y uno más el que tiene que ver con la incidencia en la vida política y organizativa de la comunidad que los maestros tuvieron y siguen teniendo y dado su entrelazamiento con las estructuras de poder caciquiles del Partido Revolucionario Institucional en el Estado, no siempre con resultados positivos y que se denota en el evidente rechazo que hacia esta participación política tiene la población por los grados de fragmentación social que ello ha implicado como se indica en la siguiente afirmación de Don Pablo: trabajo es que comenzó a haber maestros de Huehuetla ya cambio, ya comenzó a desparpajar.

Reconozco a éste como un primer momento en el cual la escuela para ir afirmando el proyecto inclusivo del estado nación mexicano, en congruencia con la forma en que éste se constituye en otros países, se va fincando en esta serie de prohibiciones al interior de la misma (uso de la lengua materna, la ropa, los mecanismos de socialización) mientras que en paralelo la figura del docente se va afianzando y ganando espacios políticos, económicos y sociales importantes, pero generando serios conflictos al interior de la comunidad.

En tanto hoy en día en Huehuetla, la escuela se considera el espacio idóneo para la formación de una serie de componentes científicos, morales, técnicos y de socialización para los niños; de tal suerte que su ingreso, permanencia y conclusión se asumen como la única circunstancia deseable en la vida infantil; el paso de un nivel a otro es causa de un gran festejo; se busca padrino o madrina, que a diferencia del ritual del bautismo, de quinceaños o boda, religiosos pues, no es necesario que sea casado; antes bien, se busca que la persona que apadrinará al estudiante que termina el ciclo, es una persona generalmente joven cuyo nivel de 
estudios y económico o bien estabilidad laboral, familiar y esquema de vida se ajusta al ideal de una persona trabajadora, que asegure que será un buen ejemplo para el ahijado; de igual forma, que esté disponible para acudir a él cuando el muchacho en su desarrollo, requiera de un consejo o llamado de atención. Éstas son las intervenciones que se esperan de los padrinos; la búsqueda y aceptación del padrino, causa tensión entre las personas y el compromiso asumido se agradece con una comida, bien, modesta o no dependiendo de las condiciones económicas de la familia. El padrino a su vez, lleva un obsequio al ahijado y le acompaña durante la ceremonia escolar; en ésta además de las autoridades civiles y educativas, las ancianas y madrinas del pueblo presiden la ceremonia; éstas últimas vestidas tradicionalmente y congregan a una gran parte de la gente del pueblo. La ceremonia, la relación con los padrinos y la reunión familiar operan de igual manera si lo que concluye un niño es el preescolar, la primaria o la secundaria. De hecho las escuelas organizan en días $u$ horarios diferenciados las ceremonias de la clausura de cursos, para posibilitar que tanto las autoridades civiles como educativas y la población acudan a éstas.

En este segundo momento no sólo la escuela se asume como el principal vehículo de inclusión social, sino que ahora acorde al planteamiento del estado mexicano en su política cultural y educativa se busca la reivindicación de la cultura indígena $^{16}$, circunstancia que no puede ser entendida al margen de los conflictos políticos acaecidos a raíz del surgimiento del ejército zapatista en el sureste mexicano y que obligó al estado mexicano a reconsiderar la diversidad cultural, abriendo así la posibilidad de legitimar social y políticamente la pervivencia de la etnicidad. Sin embargo, tal posibilidad de inclusión social, se apuntala sólo a partir del aprendizaje de conocimientos y la formación para trabajos de carácter prioritariamente industriales cuya realización en nuestro país es sólo posible en

\footnotetext{
${ }^{16}$ Circunstancia que se observa en distintos eventos en los que intervienen las escuelas (primaria, secundaria, bachillerato) en un afán por "revivir las tradiciones": para la celebración de día de muertos éstas convocan a un concurso de ofrendas y gana quien reproduzca con mayor apego los altares "de antes"; los ensayos para la representación del carnaval se hacen en las escuelas y como parte del programa artístico que se ofrece en la festividad de clausura, se reproducen danzas tradicionales.
} 
espacios urbanos, de modo que puedo afirmar que la escuela hoy en día en Huehuetla, establece como horizonte un trabajo que se aleja del tradicional, para las mujeres y los hombres, que no es el agrícola y que se desarrolla fuera de la comunidad; de ahí que se opera una relación inversa entre la consolidación sociocultural de la escuela en la comunidad y el abandono de ciertas acciones rituales de carácter étnico que privilegiaban la formación para el trabajo desde la acción comunitaria y de un trabajo que al desarrollarse posibilitaba el arraigo y el fortalecimiento comunitario; mientras que el que se privilegia ahora se aprende en el seno de la escuela -como una institución que recién viene mirándose como una construcción de la propia comunidad- pero cuyos aprendizajes y resultados de formación habrán de ponerse en práctica fuera de la comunidad y en espacios fundamentalmente urbano-industriales.

\section{Conclusiones.}

En el discurso de la filosofía y en la teoría social el trabajo viene a asumirse como el elemento nuclear del desarrollo y progreso de las sociedades. Para los ilustrados abocados al logro del progreso y utilidad social, la educación está encaminada al desarrollo de las capacidades y conocimiento del hombre a fin de que actúe sobre su medio ambiente transformándolo, esto es mediante el trabajo. La educación por tanto, habrá de ser racional y compatible con los proyectos, tanto de las unidades domésticas como en un nivel más amplio, del estado; se introducen así diferencias, sobre todo, en razón del grupo social al que se pertenece, y por el sexo. La preparación educativa en los estratos superiores habrá de ser más rica en contenidos culturales que la de las clases trabajadoras, orientada esencialmente hacia la capacitación manual; dentro de un mismo nivel, los distintos papeles sociales asignados a hombres y mujeres, fundamentados en teóricas cualidades físico-psíquicas diferenciales que hacen a aquéllas más débiles y que determinan una reducción de los contenidos intelectuales ofrecidos por la enseñanza femenina, un fenómeno que está presente especialmente en los sectores populares.

Tanto el trabajo privado, cuya realización obedece a una necesidad de valorización del capital y su espacio de realización, la industria, introducen una serie 
de transformaciones en todos los ámbitos de la vida social; en su origen se encuentra la ruptura de relaciones directas entre los sujetos productores, lo que también erosiona los lazos comunitarios y de socialización presentes en momentos históricos previos al capitalismo; muchos de los elementos de las rupturas que condicionan la vida social, se consolidan con la creación de la escuela que surge a su vez, como una institución social que condensa el proyecto de la modernidad y que introduce en su organización, muchos de los esquemas estratificantes, de control y exclusión presentes en los otros órdenes de la vida social.

La irrupción de la escolarización como espacio de aprendizaje impuso una nueva perspectiva del trabajo; Julia Varela (2004) señala que cambia ante todo la noción de trabajo productivo y se asienta la del trabajo escolar; en el caso de las sociedades tradicionales opera un triple movimiento: se cambia la noción de trabajo productivo por trabajo escolar, pero aún el trabajo productivo deja de ser el agrícola, doméstico y local y se privilegia el urbano-industrial. Lo cual deja en un mayor nivel de vulnerabilidad y contradicción social a las poblaciones que viven esta situación, tal cual fue descrito en el último apartado de este trabajo.

Esta somera revisión sobre los sentidos que se juegan en la constitución de la escuela y la irrupción del trabajo fabril, indica que apuntan hacia el mismo horizonte: una ruptura sociopolítica y cultural de la vida comunitaria, de la socialización de la población y de sus aprendizajes.

Las contradicciones de esta realidad en el marco de la globalización, son más profundas, su comprensión se complejiza en cuanto que hasta ahora, algunos de los principios con que surge el estado-nación, especialmente el de la coherencia interna de sus poblaciones, se ve cuestionada; a la vez que las difíciles condiciones de vida de la población ponen en duda el proyecto de la modernidad. En este contexto la fórmula trabajo-educación, no parece funcionar bajo el mismo patrón con el que venía funcionando; hace falta que en las Ciencias Sociales, estas contradicciones y su complejidad, sean pensadas desde un discurso que posibiliten acercamientos críticos a la realidad, de modo que el esclarecimiento de las problemáticas a las que nos enfrentamos como sociedades contemporáneas puedan ser dilucidadas y resueltas con beneficios sociales claros, con distintas intencionalidades entre las que 
destaquen la revaloración del trabajo no industrial, de formas de socialización no dependientes ni mediadas por el control político y la escuela vuelta un verdadero espacio de emancipación política.

\section{Bibliografía}

Alba, Alicia de (Coord.). Posmodernidad y educación. CESU-UNAM, México, 1994.

Ariés, Phillipe. La vida familiar en el antiguo régimen. Taurus Madrid, 2001.

Bauman, Zygmunt. Trabajo, consumismo y nuevos pobres. Gedisa, Barcelona, 1970.

Dumont, Luis. 70 Homo Hierarchicus: ensayo sobre el sistema de castas; Aguilar, Madrid, 1970.

Engels, F. El Papel del Trabajo en la Transformación del Mono en Hombre (2009), tomado de http://archivochile.com/ldeas.Autores/engelsf/engels de00022.pdf.

García Williams, Roberto. Los tepehuas, Universidad Veracruzana, México.

Gilly, Adolfo. "Un sujeto político no identificado” In: Le Monde Diplomátique. 060.

Instituto Nacional de salud pública-SEP. Primera Encuesta Nacional Exclusión, Intolerancia y Violencia en Escuelas Públicas de Educación Media Superior, 2007

Kuper Adams. Cultura: la versión de los antropólogos, Paidós, México.

Marini, Ruy Mauro. La teoría social latinoamericana: cuestiones contemporáneas, UNAM, México, 1996.

Marx, Karl. El Capital, Tomo I, Libro I, Siglo XXI, México.

Nieto Calleja, Raúl. Ciudad, cultura y clase obrera, una aproximación antropológica, Dirección de Culturas Populares, CONACULTA, UAM, México, 1997

UNICEF. Estado Mundial de la Infancia, 2007.

Varela, Julia, Urías, Fernando. La arqueología de la escuela, La Piqueta, España, 2004. 